\title{
Webmuseus de arte: aparatos informacionais no ciberespaço
}

\author{
Maria Lucia de Niemeyer Matheus Loureiro \\ Instituto de Pesquisas Jardim Botânico do Rio de Janeiro. Doutora \\ em ciência da informação (UFRJ/ECO - MCT/IBICT) \\ E-mail: mlucia@jbrj.gov.br
}

\section{Resumo}

Estudo abordando os museus de arte criados na Web (webmuseus) a partir de uma perspectiva informacional. Com a emergência e rápida expansão da Internet, surgiram na Web diferentes manifestações do fenômeno museu. Ao lado das interfaces de museus físicos, são criados e mantidos na Web sítios de arte auto-intitulados "museus" sem equivalência no espaço físico, sugerindo uma idéia de museu fortemente centrada na informação, o que contraria a definição oficial de museus (ICOM), da qual a palavra informação está ausente. A partir da análise do museu de arte como espaço, são abordadas as metáforas espaciais utilizadas com freqüência para nomear os novos ambientes criados na Web. A fim de equiparar museus de arte no espaço físico e no ciberespaço, é proposta a noção de aparato informacional.

\section{Palavras-chave}

Museu de Arte; Webmuseu; Aparato Informacional.

\section{Webmuseums of art: informational apparatuses on cyberspace}

\begin{abstract}
This study analyzes the art museums created on web (webmuseums) from an informational point of view. With the emergence and quick expansion of the Internet, different manifestations of the phenomenon "museum" arose in the web. Along side the interfaces of physical museums, websites were created and maintained as "museums", without equivalence on physical space, suggesting an idea of museum strongly centered in information and contradicting the official definition of "museum" (ICOM), characterized by the absence of the word information. From the analysis of art museum as space, the spatial metaphors frequently used to name the new environments created in the web are approached. The notion of "informational apparatus" is proposed to compare museums created in the physical space and in the cyberspace.
\end{abstract}

\section{Keywords}

Art Museum; Webmuseum; Informational Apparatus.

Ci. Inf., Brasília, v. 33, n. 2, p. 97-105, maio/ago. 2004

\author{
INTRODUÇÃO
}

$\mathrm{O}$ artigo que se segue tem origem em tese de doutorado intitulada "Museus de Arte no Ciberespaço: uma abordagem conceitual”, apresentada, em 2003, ao Programa de Pósgraduação em Ciência da Informação (IBICT/UFRJ). Inserido no complexo território da "Informação em Arte", o estudo tem como questão central os "museus" de arte construídos exclusivamente na Word Wide Web (webmuseus), sem correspondente no mundo físico.

Com a rápida expansão da Internet na última década do século XX, multiplicaram-se sítios auto-intitulados "museus", dentre os quais destacamos os museus de arte. Ostentando nomes como webmuseu, cibermuseu, museu digital ou museu virtual, tais sítios apresentam-se, com freqüência, como interfaces de instituições museológicas construídas no espaço físico, como o Louvre, o Prado ou o MOMA, que, graças à Internet, podemos "visitar" em um mesmo dia, escolhendo o melhor trajeto e o horário mais conveniente. Ao lado dessas interfaces, foram criados sítios que, embora sem equivalente no mundo físico, também se intitulam "museus" e apresentam "acervos" formados por reproduções digitais ou por obras-de-arte criadas originalmente em linguagem digital. Tal nomeação sugere uma idéia de museu permeada pela centralidade da informação, e não mais pela materialidade dos lugares e dos objetos físicos, traço que acompanhou o fenômeno museu desde suas origens, sem grandes abalos.

\section{A PROPÓSITO DO CONCEITO DE MUSEU}

Em 2001, profissionais e estudiosos do museu reunidos em Barcelona para a 20a Assembléia Geral do Icom (International Council of Museums) aprovaram emendas ao artigo 2 dos estatutos do órgão, que define o museu. A partir de então, "centros culturais e outras entidades voltadas à preservação, manutenção e gestão de bens patrimoniais tangíveis e intangíveis (patrimônio vivo e atividade criadora digital)" foram oficialmente admitidas como membros da categoria "museu".

Em 1940, Taylor (apud Teather, 1998) observara que "cada geração tem sido obrigada a interpretar essa vaga palavra 'museu' de acordo com as exigências sociais da época”. É ao ICOM que cabe, entretanto, responder oficialmente à pergunta "o que é museu?": 
"Um museu é uma instituição permanente, sem fins lucrativos, a serviço da sociedade e de seu desenvolvimento, aberta ao público, que adquire, conserva, pesquisa, comunica e exibe, para fins de estudo, educação e lazer, evidência material das pessoas e de seu meio ambiente”.

Ressalvando que se trata de uma definição do museu enquanto instituição, particularmente presa ao campo de ação da museologia, cabe ressaltar o fato de que a mesma é resultante de negociações que, ao longo do tempo, tiveram como fim "acompanhar as exigências da época” e acolher uma gama sempre crescente de organizações, algumas das quais, não claramente contempladas no corpo da definição, são relacionadas na forma de apêndices. Assim, para os propósitos da referida definição, são reconhecidos também pelo ICOM como integrantes da categoria museu, além das instituições assim designadas, inúmeros outros espaços e/ou organizações, como monumentos e sítios naturais, históricos ou arqueológicos, jardins botânicos e zoológicos, entre outros.

O reconhecimento oficial da "atividade criadora digital" como objeto da museologia atesta a atualidade e relevância do tema e, simultaneamente, desafia o pressuposto fundamental da "materialidade", presente não só no corpo da definição como nos apêndices, que tratam de expandi-la para além das organizações autodenominadas "museus", sem, no entanto, desafiá-la ou contradizê-la. A inclusão do novo apêndice autoriza, a partir de então, não apenas a acolher oficialmente os webmuseus como integrantes da categoria museu, mas, sobretudo, pensá-los a partir desse pressuposto. Um detalhe, contudo, deve ser ressaltado: a palavra informação está ausente do corpo da definição e dos apêndices que a complementam.

\section{A POÉTICA DO ESPAÇO MUSEALIZADO}

Em sua concepção moderna, a idéia de museu sustentase sobre um tripé constituído pelos elementos objeto/ espaço/informação, que se inter-relacionam e interagem. Quanto ao termo museu, de longa história, tem sua gênese na Antigüidade Clássica. Até o século XIX, constata-se, freqüentemente, o uso do vocábulo para designar catálogos, livros e enciclopédias, o que denota uma evidente associação com a idéia de informação. É só a partir do século XIX que se difunde e fortalece a conotação física e concreta da palavra museu, devendo ser sublinhado que seu uso se prende com mais freqüência aos prédios que às coleções neles abrigadas.
Ainda que autores contemporâneos venham buscando conceituar o museu e a experiência museológica por meio de abordagens mais abstratas, das quais o objeto é eventualmente suprimido, a questão da materialidade coloca-se forçosamente a cada tentativa de extingui-la. Por força de seu caráter físico, os objetos - de modo particular, as obras-de-arte - são impelidos a ocupar um espaço. Longe de ser simples continente ou receptáculo neutro, no entanto, o museu está em inevitável e incessante interação com a obra, conformando-a e modificando-a, ao mesmo tempo em que é conformado e modificado por ela.

A abordagem do museu como espaço leva inevitavelmente à arquitetura de museus, tema que ganha força inédita a partir do século XX, sobretudo quando relacionado ao debate sobre arte contemporânea. A adaptação de palácios e prédios históricos cede lugar a projetos arquitetônicos arrojados, que já não se limitam a abrigar museus e seus acervos, mas se expõem como verdadeiras obras-de-arte.

Para Kimmelman (2001, p. 8), os museus de arte contemporânea seriam encarados como as "novas catedrais" do nosso tempo, e a arquitetura como a solução para muitos dos problemas de uma instituição em crise, cuja aparência exterior se converte em um dos únicos aspectos cuja autoridade institucional não tenha sofrido desgaste. As novas prioridades do museu fazem de Bilbao, um caso emblemático, e da "casca vazia”, uma metáfora adequada, pois a posse de uma coleção torna-se dispensável.

Enfatizando a vinculação profunda entre o museu de arte e o contexto histórico de seu surgimento (uma vez que este teria ocorrido em resposta às novas demandas de autonomia da arte e dos artistas, que teriam reivindicado para si um lugar), Bechara ressalta a insuficiência de uma abordagem estritamente conceitual e abstrata do museu que não leve em consideração seu caráter espacial, material e concreto, que definiria "sua forma própria de expressão".

Embora a posse de um acervo permanente deixe de ser, eventualmente, condição sine qua non para a criação de um museu, o mesmo não se pode afirmar do espaço físico no qual são expostas ao público as obras-de-arte e demais objetos musealizados, e que se manteria firme como critério definidor da categoria museu. Ao abordarmos o conceito de "museu”, deparamo-nos muito freqüentemente com metáforas espaciais - gabinete, câmara, palácio, templo, fórum, armazém, laboratório, mausoléu - que servem quer para definir atitudes relativas 
ao fenômeno, quer para embasar modelos, quer para estabelecer posturas críticas. A origem mitológica do nome museu remete ao "templo" (das musas), o que o associa ao fenômeno da sacralização, apontado por inúmeros autores. Da crítica à sacralização, surgiria a proposta do modelo "fórum", que, por sua vez, remete também a um espaço - não de consenso ou reverência, mas de debates.

Em estudo dirigido à imaginação criadora e poética, Bachelard propõe uma topoanálise, ou seja, uma análise das imagens associadas ao espaço a partir de uma abordagem fenomenológica. Uma dessas imagens seria a da casa, segundo o filósofo "um corpo de imagens que dão ao homem razões ou ilusões de estabilidade" que serve para alojar não só nossas lembranças, mas também nossos esquecimentos (Bachelard, 1984, p. 208).

Bachelard (1984, p. 197) analisa ainda espaços como gavetas, cofres e armários - "as casas das coisas" - que trariam consigo "a estética do escondido". Referindo-se a Bergson, afirma que aquele filósofo repudiava a imagem que associa a memória com um "armário de lembranças"; sublinha, entretanto, o caráter imperioso das imagens sobre as idéias. $\mathrm{O}$ verdadeiro armário não é um móvel cotidiano:

"Quando damos aos objetos a amizade que convém, não abrimos mais um armário sem estremecer um pouco. Sob sua madeira roxa, o armário é uma amêndoa branca. Abri-lo é viver um acontecimento de brancura". (Bachelard, 1984, p. 250).

Uma "antologia do cofre" é também reivindicada pelo filósofo, para quem os móveis complexos testemunham uma "necessidade de segredos", uma "inteligência do esconderijo". Ressaltando a inexistência de fechadura totalmente resistente à violência (pois "toda fechadura é um apelo ao arrombador"), Bachelard (1984, p. 250, 252) define o cofre como o espaço onde se alojam as "coisas inesquecíveis" não só para nós, mas também "para aqueles a quem daremos os nossos tesouros". Condensando passado, presente e futuro, o cofre seria a "memória do imemorial".

Um capítulo do ensaio "A Poética do Espaço" é dedicado à porta, "cosmos do entreaberto", cuja imagem é associada simultaneamente à abertura e ao fechamento (Bachelard, 1984, p. 342). Imagens associadas ao espaço, de modo particular a da porta, revelam-se extremamente ricas para uma reflexão conceitual sobre o museu, lembrando-nos sua condição simultânea e paradoxal de obstáculo e via de acesso à arte e às obras-de-arte.
Observando a impossibilidade de "conceber qualquer coisa real exceto sob as condições do espaço e do tempo", que constituiriam "a estrutura em que toda a realidade está contida”, Cassirer (1997, p. 73) sublinha a dificuldade da filosofia em "explicar e descrever a verdadeira natureza do espaço abstrato ou simbólico”, que constituiria "uma das primeiras e mais importantes descobertas do pensamento grego". Com a invenção do espaço abstrato pela geometria, o homem deixaria de ter uma idéia de espaço imposta meramente pela "natureza díspar dos sentidos", chegando ao conceito de um "espaço homogêneo" e "universal" graças ao qual seria possível atingir a concepção de uma "ordem cósmica singular e sistemática", impensável de outro modo (Cassirer, 1997, p. 76-80).

Assim como Cassirer, Foucault (2001) ressalta o caráter sagrado dos lugares, afirmando que o espaço contemporâneo não teria sido totalmente dessacralizado. Em contraste com o século XIX - época de história e, portanto, do tempo -, nosso tempo se definiria como a época do espaço. Dentre os espaços, o autor se interessa, sobretudo, por aqueles que possuem a peculiaridade de se relacionarem e se encadearem uns nos outros: as "utopias" e as "heterotopias". Enquanto aquelas seriam "posicionamentos sem lugar real [que] mantêm com o espaço real da sociedade uma relação geral de analogia direta ou inversa", as heterotopias seriam como

“... lugares reais, lugares efetivos, lugares que são delineados na própria instituição da sociedade, e que são (...) espécies de utopias efetivamente realizadas nas quais todos os posicionamentos que se podem encontrar no interior da cultura estão ao mesmo tempo representados, contestados e invertidos, espécies de lugares que estão fora de todos os lugares, embora eles sejam efetivamente localizáveis" (Foucault, 2001, p. 415).

Exemplificando, com o teatro, o cinema e o jardim, as heterotopias que justapõem "em um só lugar real vários espaços, vários posicionamentos que são em si próprios incompatíveis", Foucault acrescenta ainda que, na maior parte das vezes, as heterotopias estão ligadas a "recortes de tempo", ou heterocronias. Do relacionamento complexo entre heterotopias e heterocronias, surgiriam as "heterotopias do tempo", próprias da cultura ocidental do século XIX, como museus e as bibliotecas. Nelas, o tempo não cessaria de se acumular sobre si mesmo:

"A idéia de tudo acumular, a idéia de constituir uma espécie de arquivo geral, a vontade de encerrar em um lugar todos os tempos, todas as épocas, todos os 


\section{Maria Lucia de Niemeyer Matheus Loureiro}

gostos, a idéia de constituir um lugar de todos os tempos que esteja ele próprio fora do tempo, e inacessível à sua agressão, o projeto de organizar assim uma espécie de acumulação perpétua e indefinida do tempo num lugar que não mudaria, pois bem, tudo isso pertence à nossa modernidade. $\mathrm{O}$ museu e a biblioteca são heterotopias próprias à cultura ocidental do século XIX.” (Foucault, 2001, p. 419).

Foucault observa ainda que as heterotopias teriam como premissa "um sistema de abertura e fechamento que, simultaneamente, as isola e as torna penetráveis". O acesso a uma heterotopia pressuporia, assim, "certa permissão e [...] certo número de gestos" (Foucault, 2001, p. 420).

O paradoxo entre acesso e exclusão leva-nos a abordar o caráter público do museu. Pomian observa que, nos séculos XVII e XVIII, a despeito do desenvolvimento e enriquecimento das coleções, a população era, em sua maioria, privada do acesso às obras acumuladas nas coleções, de caráter privado (Pomian, 1984, p. 81). De acordo com o autor, deve-se a membros dos "estratos médios" da sociedade, particularmente sábios, escritores, eruditos e artistas - para Pomian, "colecionadores virtuais" desprovidos dos meios necessários para a aquisição dos semióforos * necessários para suas atividades - a pressão para o livre acesso às coleções. As fundações de bibliotecas públicas e de museus seriam, assim, em grande parte, respostas dos detentores do poder a tais demandas particulares.

Característica contemplada pela definição do ICOM, o caráter público do museu supõe uma necessária relação entre museu e público, entendida por Weil (1999, p. 17) como "uma revolução em processo". Referindo-se aos museus de maneira geral e aos museus de arte em particular, Weil ressalta que a posição assumida em relação ao público foi, em suas origens, de clara superioridade, uma vez que o museu teria sido criado para "aumentar o nível de entendimento público (...), elevar o espírito do visitante, (...) refinar e desenvolver o gosto popular". Afirma o autor:

\footnotetext{
*O conceito de semióforo é proposto por Pomian (1984, p. 71) em estudo sobre coleções. Estas seriam um dos meios utilizados pelo homem para ligar o invisível ao visível, esferas que estiveram separadas até o Paleolítico Superior, período em que a primeira se projetaria na segunda por meio de uma nova categoria de objetos que acabaria por provocar uma fenda no interior do visível: de um lado, as coisas ou objetos úteis, consumíveis, e de outro, os semióforos, objetos "dotados de um significado", os quais, "não sendo manipulados, mas expostos ao olhar, não sofrem usura” (Pomian, 1984, p. 71).
}

“... os museus foram estabelecidos e mantidos pelos poderosos para os que não eram poderosos, pelos limpos para os que não se banhavam, pelos que sabiam para os que necessitavam saber e que podiam ir ao museu para aprender. O museu se estabeleceu para 'fazer'. O que era necessário era 'fazer' o público. $\mathrm{O}$ museu era um lugar para inculcar" (Weil, 1999, p. 17).

De acordo com o autor, diversos fatores teriam contribuído para destronar o museu do posto soberano exercido em suas origens, entre eles "a perda, ou ao menos a mácula na confiança pública do museu como instituição desinteressada, neutra e objetiva” e a "bancarrota dos fundamentos ideológicos sobre os quais se fundaram". A partir de novas formas de criação e de apreciação das obras-de-arte - já não mais firmadas sobre qualidades morais, mas em elementos formais começaria a ser desfeito "o laço entre arte e edificação moral" (Weil, 1999, p. 20).

Com a valorização dos elementos formais das obras-dearte, os museus de arte passam a ser vistos como espaços destinados à apreciação estética. A exemplo do teatro, em que o palco e a cena são valorizados por meio de artifícios voltados à anulação dos demais espaços, particularmente a platéia, o museu é proposto como espaço que se neutraliza ao ser subjugado às obras-dearte em exposição. Tal abordagem sugere a ênfase no caráter institucional do museu, traço desnudado por Bourdieu (1989, 1996) em obras que o abordam como instância de consagração e legitimação do campo artístico. Para o autor, instituições como os museus teriam como fim "oferecer à contemplação obras muitas vezes produzidas em vistas de destinações muito diferentes". Ao isolá-las e separá-las de seu contexto originário, "despoja-as de suas diversas funções religiosas ou políticas" e as reduz "à sua função propriamente artística” (Bourdieu, 1996, p. 328).

O caráter institucional - associado à sua permanência e à materialidade dos espaços e dos objetos - confere ao museu e à experiência museológica aspectos de estabilidade, durabilidade e constância. Para inúmeros autores, tais aspectos estariam relacionados, exclusivamente, à esfera do simbólico e a uma necessidade fundamentalmente humana e universal de preservação e transmissão de valores para gerações futuras. Outros os interpretam como diferentes manifestações de um mesmo fenômeno, relacionado à informação. É oportuno ressaltar que tais interpretações não são excludentes, mas complementares, e que a informação está intimamente ligada à esfera do simbólico, como sugere a nomeação dos novos territórios 
ou ambientes informacionais constituídos a partir da emergência e expansão da Internet e da Web.

Ao descrever o ciberespaço e as redes eletrônicas, é comum o recurso a metáforas oriundas do espaço físico. Uma metáfora recorrente é a do labirinto: dela se vale Lévy $(1999$, p.111) para descrever o ciberespaço, ao afirmar que esse "desenha e redesenha várias vezes a figura de um labirinto móvel, em expansão, sem plano possível, universal, um labirinto com o qual o próprio Dédalo jamais teria sonhado". Leão (1999) recorre à mesma metáfora para descrever como um percurso o processo de leitura/navegação em dispositivos hipermidiáticos.

De acordo com Rosenstiehl (1984), há duas formas diferentes e, de certo modo, antagônicas, de interpretar o labirinto, que são representadas pelas figuras do viajante e do arquiteto. $\mathrm{O}$ primeiro, desprovido de mapa, necessita decidir cada passo localmente, enquanto o segundo é capaz de uma visão externa: "o viajante errante experimenta uma sensação de infinito no labirinto, o arquiteto conhece-o como finito". Para o autor, entretanto, quem "faz" o labirinto é o viajante (e não o arquiteto), uma vez que ele "não é uma arquitetura, uma rede no sentido de quem o projeta e concebe, mas o espaço que se desdobra diante do viajante que progride, sem mapa, na própria rede" (Rosenstiehl, 1984, p. 251).

Um labirinto teria, para o autor, três características que o distinguem e que se prenderiam à figura do viajante: "a fascinação que (...) irradia pelo seu apelo à exploração", sua "condição humilde" de explorador sem mapa e a "inteligência astuciosa" que é obrigado exercitar "para conseguir caminhar até o fim, sem cair nas armadilhas das infinitas circunvoluções". Em relação às suas estruturas, entretanto, é preciso recorrer à visão global do arquiteto para distingui-los: o mais simples - o unicursal - só pode ser percorrido de uma maneira pelo viajante, e sua particularidade residiria "apenas nas circunvoluções da linha". Desprovidos de bifurcações, "logo sem possibilidade de escolha para o viajante", não seriam, entretanto, labirintos propriamente ditos, "porque negam o fio de Ariadne": a condição e sentido de um labirinto dependem da existência de ramificações ou encruzilhadas (Rosenstiehl, 1984, p. 252, 256).

Nenhuma metáfora supera, entretanto, em freqüência, a da navegação, a qual sugere a aproximação da Internet com a imagem impregnada de simbolismos do oceano. Este, por sua vez, sugere um ambiente simultaneamente hostil e fascinante, com suas marés, seu ritmo oscilante e imprevisivel, remetendo às idéias de desbravamento, aventura, exploração e fascínio pelo desconhecido.

O termo navegação designa a arte de conduzir uma embarcação, referindo-se, portanto, ao ato de navegar, que significa "percorrer o mar - e, por extensão, a atmosfera e o espaço cósmico - em navio, embarcação, aeronave, astronave ou outro veículo"* Q Quanto à imagem do barco, é abordada por Foucault como "pedaço de espaço flutuante, um lugar sem lugar, que vive por si mesmo, que é fechado em si e ao mesmo tempo lançado ao infinito do mar". Ressaltando sua penetração na simbologia ocidental, o autor observa que o navio é a heterotopia por excelência, acrescentando que nas civilizações sem barcos "os sonhos se esgotam, a espionagem substitui a aventura e a polícia, os corsários" (Foucault, 2001, p. 421).

Os portais são também metáforas recorrentes no ciberespaço e remetem à imagem da porta - "cosmos do entreaberto" - que esquematizaria "duas possibilidades fortes, que classificam claramente dois tipos de devaneios. Às vezes, ei-la bem fechada, aferrolhada, fechada com cadeado. Às vezes, ei-la aberta, ou seja, escancarada" (Bachelard, 1984, p. 342).

O uso freqüente da palavra portal para nomear sítios na Web é bastante sugestivo, remetendo ao limiar entre dois mundos: o ciberespaço teria, assim, uma realidade independente e autônoma em relação ao mundo físico, constituiria um outro mundo a ser colonizado e explorado, o que retorna, de certa forma, à idéia de navegação como desbravamento. A existência de inúmeros portais ou entradas para o ciberespaço sugere a inexistência de início, meio e fim: trata-se de um ambiente acentuadamente hipertextual, condição enfatizada por inúmeros autores contemporâneos.

\section{O MUSEU DE ARTE COMO APARATO INFORMACIONAL}

Ao propormos a noção de "aparato informacional", não pretendemos desconhecer as demais dimensões do empreendimento humano designado como museu, mas, tão-somente, reforçar e valorizar o que consideramos um de seus aspectos mais pujantes. O termo vem do latim apparatus - em sentido próprio "preparação, preparativos", e, em sentido figurado, "pompa, suntuosidade". Ainda que os dois sentidos possam, sob diferentes aspectos, contemplar o museu, optamos por deter-nos no sentido próprio da palavra que, em latim,

*FERREIRA, Aurélio B. de Hollanda. Novo Dicionário da Lingua Portuguesa. 2. ed. Rio de Janeiro: Nova Fronteira, 1986. 1838 p. 
designa "petrechos, aparelhos (máquinas, instrumentos, equipagens...)" e, em nossa língua, é definida como "conjunto de elementos materiais específicos de que se lança mão para mostrar poder, força, erudição, etc”. *

Abordando as relações entre o homem e as máquinas, Santaella observa:

"Definir o que é máquina não é simples. Num sentido mais amplo, a palavra se refere a uma estrutura material ou imaterial, aplicando-se a qualquer construção ou organização cujas partes estão de tal modo conectadas e inter-relacionadas que, ao serem colocadas em movimento, o trabalho é realizado como uma unidade" (Santaella, 1997, p. 33).

Como aparatos informacionais, os museus produzem e processam informações extraídas dos itens de suas coleções - individualmente ou em conjunto - de modo a gerar novas informações. Tais operações podem ser realizadas internamente, no âmbito de suas atividades de rotina (particularmente a documentação e a exposição), ou externamente, por estudiosos que invocam objetos como testemunhos ou recorrem aos mesmos na qualidade de documentos. Ao propormos o museu como "aparato informacional", além de reconhecer em sua estrutura aspectos de "máquina" conforme definida por Santaella, pretendemos colocar em destaque seu papel ativo como produtor de informação, a qual ultrapassa a mera função de mediador.

Tal visão leva a Latour, que destaca o caráter prático e material da produção da informação. A formação de coleções ou a "mobilização do mundo" - reunião física de elementos originalmente dispersos no espaço e no tempo - é vista pelo autor como a primeira e indispensável etapa de um ciclo cuja finalidade é transferir o mundo para locais peculiares, denominados "centros de cálculo" (bibliotecas, laboratórios e coleções). Nestes, ocorreria um "ciclo de acumulação", que resultaria na assimetria entre dois lugares, posicionados como centro e periferia (Latour, 1985).

Outras abordagens privilegiam também, sob diferentes aspectos, a dimensão informacional dos espaços musealizados: Grasskamp (1994) traça um paralelo entre as formas "museu" e "enciclopédia", modelos de representação de mundo estreitamente ligados no século XVIII, período em que desfrutavam ampla aceitação e a partir do qual se desenvolveriam em direções opostas. O termo "museu" terminaria por consolidar sua

*FerreirA, Aurélio B. de Hollanda. Novo Dicionário da Lingua Portuguesa. 2. ed. Rio de Janeiro: Nova Fronteira, 1986. 1838 p.

designação atual, passando a restringir-se às coleções de objetos e aos prédios que as abrigam, enquanto a enciclopédia, por sua vez, vincular-se-ia cada vez mais fortemente à informação.

A associação entre museu e enciclopédia já havia sido ressaltada por Otlet em 1937, ao abrir, em Paris, os trabalhos do Congresso Mundial da Documentação Universal, ocasião em que se referiu ao Mundaneum como o "museu documental universal". De acordo com Otlet, o museu deveria ser, "em face dos objetos, de sua apresentação e verificação [...] o que é a enciclopédia para os documentos gráficos” (Otlet, 1937).

Melonio aborda os museus do século XIX e os situa na confluência de três grandes tendências: "a visão enciclopédica, a exaltação da mercadoria e a reivindicação democrática". Interpretando o museu como "uma enciclopédia exposta a olhares concupiscentes, como nos bazares ou grandes magazines", a autora afirma, entretanto, que "o desejo de salvar a memória do mundo e enclausurar o universo no livro se dá de modo muito mais sistemático nos dicionários ou nas enciclopédias" (Melonio, 1998, p. 278, 286).

Segundo a mesma autora, Pierre Larousse teria qualificado o século XIX como "o século dos dicionários" e aproximado as formas enciclopédia e museu, ao afirmar que, enquanto "o dicionário, com seus numerosos exemplos, é um museu”, este é, em por sua vez, "um empilhamento ou uma justaposição de enciclopédias": ambas as formas ofereceriam um "resumo do universo" e uma "exposição do saber" (Larousse apud Melonio, 1998, p. 286).

Associado à utopia da universalidade, à ambição da completude e ao enclausuramento do mundo, tendo como premissa o direito de acesso a determinados bens pelos cidadãos, o que implicaria, forçosamente, a preservação e o arquivamento contínuos, o museu moderno emergeria em um contexto de valorização da informação.

Projetando a questão para a contemporaneidade, Colombo (1991) refere-se à "mania arquivística" ou "obsessão da memória” característica do século XX que, a seu ver, assumiria formas diversas: a gravação ("memorização de um fato em um suporte por meio de uma imagem”), o arquivamento ("tradução do evento em informação cifrada e localizável dentro de um sistema”), o arquivamento da gravação ("tradução de uma imagem-recordação, de um ícone mnemônico em um signo arquivístico e localizável no sistema”) e a gravação do arquivamento ("produção de cópias dos signos já arquivados a fim de evitar-se um possível esquecimento”). 
Tais práticas, de acordo com o autor, serviriam para "descrever um universo de catalogação do presente" cujo paradoxo residiria na "transformação dos objetos do hoje em ontem” (Colombo, 1991, p.17-18).

O contínuo arquivamento da memória implica a existência de locais equipados para tal fim - ou seja, de aparatos informacionais. Nestes, estaria implícito o papel de documento desempenhado pelos objetos integrantes de suas coleções - o que presumiria o prévio alargamento do conceito de documento para além dos textos escritos.

Autores como Paul Otlet e Suzane Briet, ligados ao movimento da Documentação, foram retomados por Buckland nos artigos "Information as Thing" e "What is a 'document?", ambos publicados no Journal of American Society for Information Science, respectivamente em 1991 e 1997. Entre as principais definições de informação, o autor identifica três grandes grupos: o primeiro interpretaria a informação como processo relacionado à mudança ocasionada pelo ato de informar; o segundo ressalta a natureza intangível da informação e a associa ao conhecimento. Sob o rótulo "informação como coisa", por fim, o autor reúne um terceiro grupo de definições que reivindicam o uso do termo para nomear não apenas objetos, vistos como "fenômenos informativos", mas também as representações de informações do segundo grupo, de especial interesse nos chamados "sistemas de recuperação de informações", uma vez que, para serem manipuladas, as informações necessitariam ser representadas em meio físico, assumindo, assim, caráter tangivel (Buckland, 1991, p. 352-353).

Em seu "Tratado de Documentação", publicado em 1934, Otlet desenvolveria uma visão funcional de documento e estenderia o conceito para além dos registros gráficos e escritos que representem idéias ou objetos, ou seja, para os objetos em si mesmos, a partir do reconhecimento de que se é 'informado' por meio de sua observação. Em 1906, segundo Rayward (1997), Otlet teria criado uma base de dados de imagens (o Repertório Iconográfico Universal) que contava, seis anos depois, com $250 \mathrm{mil}$ registros.

Quanto a Briet (apud Buckland, 1997), acrescentaria novos elementos no manifesto sobre a natureza da documentação que publicou, em 1951, sob o título "Qu'est-ce que la Documentation?", no qual identifica a noção de documento com evidência física. Para a autora, documento seria "todo índice concreto ou simbólico, conservado ou registrado para as finalidades de representar, reconstituir ou provar um fenômeno físico ou intelectual". Embora afirmando que não são claras as regras de Briet para que um objeto se torne documento, Buckland (1997) infere de suas idéias os seguintes critérios: materialidade, intencionalidade e processamento. Da última condição, deduz ainda sua posição fenomenológica, uma vez que "o objeto deve ser percebido como documento".

Perseguindo a noção de informação como evidência, o autor adverte que a ciência da informação privilegiou tradicionalmente os dados e documentos textuais como recursos de informação, em detrimento dos eventos e objetos potencialmente informativos. Observando que "objetos são coletados, armazenados, recuperados e examinados como informação", questiona a completude de "qualquer visão de informação, ciência da informação ou sistemas de informação que não sejam estendidos aos objetos", acrescentando ainda que, embora alguns objetos informativos - como prédios históricos, por exemplo - não sejam passíveis de coleta e armazenamento, ou seja, de relocação física, podem vir a integrar coleções virtuais por meio de suas representações. Ressalta, ainda, que o principal atributo da informação-como-coisa - "ser informativo" - é situacional, pois seu caráter informativo depende de uma combinação de circunstâncias que devem ser examinadas para que se presuma a necessidade de preservação e/ou de representação (Buckland, 1997).

\section{WEBMUSEUS DE ARTE COMO APARATOS INFORMACIONAIS}

A despeito das inúmeras e significativas diferenças entre museus construídos na Web e no espaço físico, o nome museu (acompanhado de prefixos ou adjetivos como ciber, Web, digital e virtual) tem sido freqüentemente adotado para nomear sítios de arte construídos na Web. Embora ressaltando a fundamental novidade e complexidade do fenômeno - cujo potencial para gerar novas realidades e objetos exigirão a criação de um novo vocabulário -, o crescente emprego de terminologia museológica (museu, exposição, acervo, coleção) e de referências visuais ao seu espaço físico (como galerias e salas de exposição) evidencia uma associação intencional com o museu que transcende a pura e simples evidência de que ambos são criados para acolher e dar acesso à obra-de-arte (traço também presente em galerias e publicações de arte) ${ }^{*}$.

\footnotetext{
*Dentre os webmuseus analisados em nosso estudo, destacamos alguns: MUVA / Museu Virtual de Artes El Pais (http://www.elpais.com.uy/ muva/); MVAB / Museu Virtual de Arte Brasileira (http:// www.museuvirtual.com.br/); Net Art Museum( http://www.netartmuseum.org); MECA / Museum of Ephemeral Cultural Artifacts ( http://www.edgechaos.com/ MECA/MECA.html); MOWA/Museum of Web Art (http://www.mowa.org), Lin Hsin Hsin Art Museum (http://www.lhham.com.sg/).
} 
Partindo do princípio de que obras-de-arte (físicas ou digitais) possuem potencial informativo e que museus de arte (construídos na Web ou no espaço físico) podem desempenhar funções informacionais análogas, acreditamos ser seu ponto tangencial a informação. Propomos, assim, que ambos sejam equiparados a partir da noção de "aparato informacional", cuja definição apresentamos a seguir:

Qualquer organização / ambiente construído com a intenção de produzir, processar e transferir informações, que reúna (fisica ou virtualmente), conserve, documente, registre, pesquise e comunique evidências (materiais ou imateriais) das pessoas e/ou de seu meio ambiente, por meio de originais ou reproduções de qualquer natureza, mantendo interface com a sociedade de modo a propiciar visibilidade / acesso às suas coleções e informações.

Caracterizar os webmuseus como aparatos informacionais implica, entretanto, novo alargamento do conceito de documento, para além do que já haviam promovido Otlet e Briet, pois no conceito de documento digital (Buckland, 2000) está implícita a renúncia à materialidade como critério definidor.

Cabe ainda ressaltar o papel desempenhado pela tecnologia como fator de aproximação entre a ciência da informação e áreas voltadas para a representação da obra-de-arte (como os museus e bibliotecas de arte), fato observado por Pinheiro (2000). Quanto à Internet e à Web, por sua própria configuração, propiciariam condições favoráveis à construção de "aparatos informacionais", ambientes voltados à produção e à transferência de informações. Alguns de seus aspectos, como a estrutura em hipertexto, foram salientados por Gomes (2002, p. 111) em estudo sobre bibliotecas virtuais. Observando que estas últimas são resultantes de um "trabalho intelectual", a autora enfatiza ainda "a participação de atores humanos para a sua estruturação".

Essa característica aproxima também museus construídos no espaço físico e no ciberespaço. $O$ ato de reunir (física ou virtualmente) um conjunto de obras é sempre intencional e pressupõe um trabalho de seleção e coleta, que é condição essencial, embora insuficiente, para que se realize a transferência de informações. Esse aspecto é ressaltado por Barreto (1999), ao definir o "repositório de informação" como um "estoque potencial de conhecimento". Sua existência, embora imprescindível, é insuficiente para a transferência de informação, uma vez que a produção do conhecimento "só se efetiva a partir de uma ação de comunicação mutuamente consentida entre a fonte (os estoques) e o receptor".
Por sua amplitude planetária, a Internet potencializaria as condições de acesso a estoques de informação e de efetivação de ações de comunicação, ao deixar de se sujeitar a empecilhos geográficos. Outras barreiras, entretanto, permanecem e tendem a se aprofundar. Observando que "a globalização econômica e eletrônica só atende a alguns planos da transferência da informação, aqueles sujeitos às condições físicas e econômicas de disponibilidade e acesso", González de Gómez (1995, p.9) enfatiza outros empecilhos - designados como "diferencial pragmático" - resultantes "da assimetria dos participantes dos pólos de emissão e recepção".

A partir dessa síntese e, sobretudo, do conjunto de conceitos, noções e reflexões dos autores nos quais baseamos nosso estudo, propomos uma definição que contemple as especificidades dos webmuseus. Tratandose, como já ressaltamos, de um fenômeno extremamente recente e, por natureza, dinâmico, advertimos tratar-se de uma construção necessariamente contextual, provisória e aberta a estudos e reflexões futuras:

Webmuseus de arte são sítios construídos e mantidos exclusivamente na Web, destinados a reunir virtualmente e a expor obras-de-arte geradas originalmente por processos de síntese, ou, por meio de cópias digitais, obras-de-arte que existem (ou existiram) no espaço físico. As características da Internet lhes conferem configuração hipertextual, propiciando a conectividade e ampliando as possibilidades de interação com a obra, cuja(s) abertura(s) é(são) evidenciada(s) e/ou potencializada(s), além de condições peculiares de acesso, eliminando empecilhos espaciais e temporais e impondo, por outro lado, restrições de ordem cognitiva e tecnológica, assim como barreiras lingüísticas. Diferem dos museus físicos, ainda, por seu caráter provisório e não necessariamente institucional, bem como pela imaterialidade inerente à imagem digital. Suas finalidades abrangem e, eventualmente, ultrapassam a educação e o lazer, podendo incluir propostas de participação em processos criativos. Compartilham com os museus de arte construídos no espaço físico características e funções que os equiparam como aparatos informacionais: destinam-se a produzir, processar e transferir informações e mantêm interface com a sociedade de modo a propiciar visibilidade/ acesso a suas coleções e informações.

Julgamos oportuno mencionar, ainda uma vez, a dificuldade de nomear um fenômeno novo, para o qual as palavras mostram-se insuficientes ou impróprias. Dentre as denominações mais freqüentes, destacamos museu digital, cujo qualificativo ressalta simultaneamente sua linguagem e sua natureza imaterial, mas não dá conta 
da especificidade da rede; netmuseu, cibermuseu ou webmuseu, cujos prefixos remetem às especificidades da Internet, enfatizando o espaço desterritorializado das redes, aplicando-se, entretanto, indistintamente, aos museus construídos na Web e aos sítios mantidos por museus físicos; e museu virtual, denominação que parece tender a se consolidar.

Alertando para o perigo do confundir o virtual com o possível, Deleuze (1988, p. 339) observa que, enquanto este se opõe ao real, aquele possui "plena realidade por si mesmo". Enquanto o possível tende a se realizar, o virtual, por seu lado, tende a se atualizar. Retomando Deleuze, Lévy (1996, p. 17-18) aborda a virtualização como o "movimento inverso ao da atualização", ou seja, o movimento de passagem do ato à potência. Um dos principais traços do virtual seria o "desprendimento do aqui e agora”. Virtualizar uma mensagem implicaria, assim, afastá-la de seu emissor, desatrelando-a de seu tempo e espaço de criação, libertá-la de seu contexto. Desterritorializado e ubíquo, um museu construído na web é, de fato, virtual. Nomeá-lo como "museu virtual" significa, contudo, assumi-lo como uma virtualização do museu físico e, simultaneamente, recusar a este último o mesmo qualificativo: museus de arte construídos no espaço físico são, também, museus virtuais.

\section{Artigo recebido em 15-06-2004 e aceito para publicação de 18 a $21 / 10 / 2004$.}

\section{REFERÊNCIAS}

BACHELARD, Gaston. A poética do espaço. 2. ed. São Paulo : Abril Cultural, 1984. p. 181-354. (Os pensadores).

BARRETO, Aldo. Os destinos da ciência da informação: entre o cristal e a chama. DataGramaZero - Revista de Ciência da Informação, dez. 1999. Disponível em: <http://www.dgz.org.br/dez99/F_I_aut.htm>. Acesso em: dez. 2000.

BECHARA, Adriano F. Arquitetura de museus e recepção estética. Disponível em: <http://www.fflch.usp.br/dh/ceveh/public_html/ biblioteca/artigos/ >. Acesso: jun. 2002.

BOURDIEU, Pierre. As regras da arte: gênese e estrutura do campo literário. São Paulo: Companhia das Letras, 1996. 431 p.

\section{298 p.}

O poder simbólico. Lisboa : Difel; Rio de Janeiro : Bertrand,

BUCKLAND, Michael K. Information as thing. Journal of American Society for Information Science, v. 42, n. 5, p. 352-360, 1991 (a).

What is a digital document? Disponível em: < http:// www.sims.berkeley.edu/ ${ }^{\sim}$ buckland/digdoc.html $>$. Acesso em: dez. 2000.

. What is a document? Journal of American Society for Information Science, v. 48, n. 9, p. 804-809, 1997.

CASSIRER, Ernst. Ensaio sobre o homem: introdução a uma filosofia da cultura humana. São Paulo : Martins Fontes, 1997. 391 p.

COLOMBO, Fausto. Os arquivos imperfeitos. São Paulo : Perspectiva, 1991. $134 \mathrm{p}$.
DELEUZE, Gilles. Diferença e repetição. Tradução Luis Orlandi, Roberto Machado. Rio de Janeiro : Graal, 1988. 499 p.

FOUCAULT, Michel. Outros espaços. In: Ditos e escritos III. Rio de Janeiro : Forense Universitária, 2001. p. 411-422.

GOMES, Sandra Lúcia Rebel. Bibliotecas virtuais: informação e comunicação para a pesquisa científica. 2002. 283 f. Tese (Doutorado em Ciência da Informação) - Instituto Brasileiro de Informação em Ciência e Tecnologia, Universidade Federal do Rio de Janeiro, Rio de Janeiro, 2002.

GONZÁLEZ DE GÓMEZ, Maria Nélida. Informaç̃o: dos estoques às redes. Ciência da Informação, Brasília, v. 24, n. 1, p. 77-83, jan./abr. 1995.

GRASSKAMP, Walter. Reviewing the museum or: the complexity of things. Nordisk Museologi, v. 1, p. 65-74, 1994. Disponível em:< http:/ /www.nordiskmuseologi.com/EngArt/Grasskamp.html >. Acesso em: maio 1997.

KIMMELMAN, Michael. O futuro dos museus no século XXI. Jornal do Brasil, Rio de Janeiro, 11 set. 2001, p. 8.

LATOUR, Bruno. Les 'vues' de l'esprit: une introduction a l'anthropologie des sciences et des téchniques. Culture Téchnique, n. 4, p. 5-29, 1985. Edição especial.

LEÃO, Lúcia. O labirinto da hipermídia: arquitetura e navegação no ciberespaço. São Paulo : Iluminuras, 1999.

LÉVY, Pierre. Cibercultura. São Paulo : Ed. 34, 1999. 159 p.

O que é o virtual? São Paulo : Ed. 34, 1996. p. 97.

LOUREIRO, Maria Lucia de Niemeyer Matheus. Museus de arte no ciberespaço: uma abordagem conceitual. 2003. 206 f. Tese (Doutorado em Ciência da Informação) - Instituto Brasileiro de Informação em Ciência e Tecnologia, Universidade Federal do Rio de Janeiro, Rio de Janeiro, 2003.

MELONIO, Françoise. La culture comme héritage. In: BAECQUE, Antoine de; MELONIO, Françóise. Histoire culturelle de la France. lumière et liberté: le dix-huitième et dix-neuvième siècles. Paris : Editions du Seuil, 1998. p. 245-290.

OTLET, Paul. Documentos e documentação. In: CONGRESSO MUNDIAL DA DOCUMENTAC̣ÃO UNIVERSAL, 1937, Paris. Disponivel em: http://www.conexaorio.com/biti/otlet/. Acesso em: abr. 2002.

PINHEIRO, Lena Vania Ribeiro, GONZÁLEZ DE GÓMEZ, Maria Nélida. (Org.). Interdiscursos da ciência da informação: arte, museu, imagem. Rio de Janeiro; Brasília : IBICT/DEP/DDI, 2000. 228 p.

POMIAN, Krzysztof. Coleção. In: ENCICLOPÉDIA Einaudi. Lisboa : Imprensa Nacional, Casa da Moeda, 1984. v. 1, p. 51-86.

RAYWARD, W. Boyd. The origins of information science and the International Institute of Bibliography/International Federation for Information and Documentation. Journal of the American Society for Information Science, n. 48, p. 289-300, Apr. 1997. Disponível em: http://alexia.lis.uiuc.edu/ ${ }^{\sim}$ wrayward/otlet/OriginsofInfoSci.htm. Acesso em: jun. 2002.

ROSENSTIEHL, Pierre. Labirinto. In: ENCICLOPÉDIA Einaudi. Lisboa : Imprensa Nacional, Casa da Moeda, 1984 (a). v. 13, p. 247-273.

SANTAELLA, Lucia. O Homem e as máquinas. In: DOMINGUES, Diana (org.). A Arte no século XXI: a humanização das tecnologias. São Paulo: Ed. da UNESP, 1997. p. 33-44.

TEATHER, Lynne. A Museum is a museum is a museum ...Or is it? Exploring Museology and the Web. Disponivel em: <http://www.archimuse.com/ mw98/papers/teather/teather_paper.html> Acesso: jul. 1998.

WEIL, Stephen E. El Museo y el publico. Revista de Museologia, ano 5, n. 6, feb. 1999. Madrid. 